\title{
Mors Gaudet Succurrere Vitae. The Role of Clinical Autopsy in Preventing Litigation Related to the Management of Liver and Digestive Disorders
}

\author{
Stefano D'Errico ${ }^{1}{ }^{1}$, Martina Zanon ${ }^{1}$, Michela Peruch ${ }^{1}$, Monica Concato ${ }^{1}$, Martina Padovano ${ }^{2}$, \\ Alessandro Santurro ${ }^{2}\left(\mathbb{D}\right.$, Matteo Scopetti ${ }^{2, *}$ (i) and Vittorio Fineschi ${ }^{2}{ }^{\mathbb{D}}$ \\ 1 Department of Medicine, Surgery, and Health, University of Trieste, Strada di Fiume 44, 34149 Trieste, Italy; \\ sderrico@units.it (S.D.); martina.zanon@virgilio.it (M.Z.); michela.peruch95@gmail.com (M.P.); \\ monica.concato@studenti.units.it (M.C.) \\ 2 Department of Anatomical, Histological, Forensic and Orthopaedic Sciences, Sapienza University of Rome, \\ Viale Regina Elena 336, 00185 Rome, Italy; martina.padovano@uniroma1.it (M.P.); \\ alessandro.santurro@uniroma1.it (A.S.); vittorio.fineschi@uniroma1.it (V.F.) \\ * Correspondence: matteo.scopetti@uniroma1.it; Tel.: +39-0649912796
}

check for updates

Citation: D’Errico, S.; Zanon, M.; Peruch, M.; Concato, M.; Padovano, M.; Santurro, A.; Scopetti, M.; Fineschi, V. Mors Gaudet Succurrere Vitae. The Role of Clinical Autopsy in Preventing Litigation Related to the Management of Liver and Digestive Disorders. Diagnostics 2021, 11, 1436. https://doi.org/10.3390/

diagnostics 11081436

Academic Editor: Elizabeth Soilleux

Received: 6 July 2021

Accepted: 3 August 2021

Published: 9 August 2021

Publisher's Note: MDPI stays neutral with regard to jurisdictional claims in published maps and institutional affiliations.

Copyright: (c) 2021 by the authors. Licensee MDPI, Basel, Switzerland. This article is an open access article distributed under the terms and conditions of the Creative Commons Attribution (CC BY) license (https:// creativecommons.org/licenses/by/ $4.0 /)$.

\begin{abstract}
Over the last 50 years, the number of clinical autopsies has decreased, but their role in assessing cause of death and clinical performance is still acknowledged. Few publications have studied their role in malpractice claim prevention. The paper aims to highlight the role of clinical autopsy in preventing errors and improve healthcare quality. A retrospective study was conducted on 28 clinical autopsies performed between 2015 and 2021 on patients dead unexpectedly after procedures for the diagnosis and treatment of digestive and hepatic diseases. After an accurate analysis of medical records and consultation with healthcare professionals, all cases were subjected to autopsy and histopathology. The data obtained were analyzed and shared with the risk-management team to identify pitfalls and preventive strategies. Post-mortem evaluations confirmed the clinical diagnosis only in six cases (21.4\%). Discordances were observed in 10 cases (35.7\%). In the remaining 12 cases $(42.9 \%)$ the clinical diagnosis was labeled as "unknown" and post-mortem examinations made it possible to document the cause of death. Post-mortem examinations can concretely enrich hospital prevention systems and improve patient safety. The methodological approach outlined certainly demonstrates that, even in the risk-management field, "mors gaudet succurrere vitae" ("death delights in helping life").
\end{abstract}

Keywords: hospital autopsy; digestive and liver diseases; error prevention; risk management; adverse events; gastroenterology claims; patient safety; healthcare quality

\section{Introduction}

The management of adverse events in medicine is a major challenge for different health systems around the world. Over the years, the approach to clinical risk has seen the use of different reactive and proactive methods. In this regard, hospital legal medicine unquestionably constitutes a privileged observatory in relation to the dual activity of clinical autopsy and litigation management. In fact, despite being historically involved in the management of claims, legal medicine is fully involved with clinical risk management and patient safety and carries out hospital autopsies to improve a policy of transparency and as a tool for measuring the quality of performance.

Regarding the autopsy, the assessment represents the gold standard for establishing the cause of death and constitutes a crucial aid for evaluating the management and performance of the healthcare structure; in fact, many studies emphasize its role in the continuous evolution of medical science [1,2], both in the forensic field and clinical setting. Post-mortem investigations in the clinical setting also allow the accurate reconstruction of 
care pathways to determine the repercussions of health treatments on the patient due to the possibility of integrating the objective findings with the evidence inferable from the analysis of the health documentation and from the direct comparison with the professionals [3-6]. The autopsy permits the ensuring of transparency through the active involvement of wards and families [7]. In fact, in the case of suspected medical professional liability, the autopsy enables useful objectivity for the evaluation of medical conduct and for ascertaining the reality of the alleged facts; such an assumption clarifies the considerable implications in the dynamics of litigation prevention and reduction of the costs of medical liability [8].

The phenomenon of defensive medicine currently represents a significant element in the decrease in hospital autopsies $[9,10]$. In particular, the fear of possible litigation entails the renunciation of a fundamental diagnostic tool for the clarification of clinical questions and related to the effects of some pathologies on the individual [11,12].

The reconstruction of the interventional modalities and the identification of the precise pathophysiological mechanisms underlying the death allow orienting the management and care policy of the facilities. Autopsy findings represent a fundamental tool for risk mapping, root cause analysis, and identification of adverse events. Although often considered an unnecessary assessment in relation to costs, autopsy therefore plays a key role in the quality and cost containment of healthcare [13].

As regards claims management, the specialties most involved in litigation are represented by the surgical branches with preponderance of gynecology and general surgery [14,15]. In the United States, over 15\% of practicing general surgeons face malpractice claims; according to further studies, almost all general surgeons over the age of 65 faced at least one complaint of professional malpractice during his or her career [16]; furthermore, it has been estimated that in the United States a physician spends an average of 50.7 months over a 40 -year career in claims that in more than $70 \%$ of cases do not involve any sentence or payment [17]. As for gastroenterology, the rate of claims paid per 1000 physicians each year has declined over the past two decades; but the average payment amounts showed an increase. Claims paid refer mainly to harmful events caused by presumed diagnostic or therapeutic (mainly surgical) errors. Most of the damage resulting from inadequate gastroenterological behaviors is serious and even includes death. About $14 \%$ of gastroenterologists face medical liability claims each year, but only $2 \%$ of claims are actually paid. In detail, $78.3 \%$ of the doctors involved in the claims are between the ages of 35 and 54 and $66 \%$ of the total have a previous history of claims. The main reasons behind the claims are represented by the misdiagnosis and the inadequate execution of a procedure; with specific reference to this last aspect, $52 \%$ of the claims concern procedures on the large intestine, $16 \%$ procedures on the gallbladder and biliary tract, and $11 \%$ procedures on the esophagus [18]. Data collected by the Physician Insurers Association of America states that gastroenterological disputes represent only $1.8 \%$ of all claims; $25 \%$ of these ended with a verdict or agreement between doctor and patient, $70 \%$ with a waiver or rejection, while the remaining 5\% with a favorable outcome for the doctor [19,20]. In Italy, data relating to health disputes at the national level are not available, but in the last decade, the rate of claims has grown in parallel with the increase in the average amount paid per claim reported [21]. Regardless of the wide variability between the international legislative frameworks, the autopsy evaluation represents an undisputed tool for preventing litigation, so much so that it deserves to be routinely included in the diagnostic path of deaths not clinically defined to guarantee objectivity and transparency.

So far, only a few studies have framed the autopsy as a possible useful tool in reactive risk management [22-24]. Given the topicality and significance of the problem, the present study aims to demonstrate the importance of clinical autopsy in deaths following imaging, endoscopic, or surgical procedures for the diagnosis and treatment of digestive and hepatic diseases. In particular, the comparison of post-mortem findings with clinical evidence will emphasize the role of clinical autopsy in identifying the suboptimal steps of care paths as well as driving the policies on quality and patient safety. 


\section{Materials and Methods}

A retrospective study was conducted on 28 clinical autopsies performed between 2015 and 2021. The inclusion criteria were: (1) sudden unexpected deaths; (2) recent (less than 30 days) imaging, endoscopic, or surgical procedures; and (3) clinical diagnosis of digestive and hepatic disease; the term of 30 days has been identified by convention as the surgical outcomes can be considered stabilized in this time frame. The exclusion criteria were: (1) autopsy ordered by the prosecutor (judicial autopsy); and (2) older (over 30 days) imaging, endoscopic, or surgical procedures. During the enrollment phase, no limits were set regarding age, length of stay, and type of procedure performed.

Preliminarily to each autopsy, accurate analysis of the medical records was carried out; besides, there was a consultation with the health professionals implicated in the care of the deceased. All the examinations were executed in the presence of medical consultants from the ward and the family of the deceased-as well as the pathologist.

Consistent with current protocols [25-28], the autopsy was performed with an external and internal examination. For each autopsy, a targeted technical approach was identifiedoriented based on the patient's clinical features and the formulated diagnostic suspicion- to determine the natural cause of death or the relationship with inadequate healthcare. The external examination was aimed at investigating the possible presence and condition of the surgical site as well as detecting additional signs of the primary disease and the medical care (e.g., signs of acupuncture); moreover, it made it possible to detect the aids used during the healthcare path (such as central venous catheters, respiratory supports, and bladder catheters). During the internal examination, all body cavities were investigated; particular attention was devoted to studying the body districts involved in diagnostic and therapeutic procedures. All examinations were completed by taking samples of organs and tissues for subsequent microscopic investigations.

The carrying out of histopathological examinations involved the microscopic observation of preparations stained with the hematoxylin-eosin technique starting from samples taken during autopsy suitably formalin-fixed and paraffin-embedded (FFPE).

The obtained data were analyzed, compared with clinical diagnoses, and shared with the risk-management team to identify pitfalls and preventive strategies.

Considering the sample size, the descriptive intent of the study, and the impossibility of identifying comparable groups for statistical purposes, a descriptive statistical analysis was carried out with the calculation of the frequencies in absolute and relative terms.

\section{Results}

The study included a sample of 28 cases of patients who died unexpectedly following procedures for the diagnosis and treatment of digestive and liver diseases between 2015 and 2021 (Table 1).

Table 1. Summary of the 28 cases included in the study.

\begin{tabular}{|c|c|c|c|c|c|c|}
\hline Case & Gender & Age & Admission Diagnosis & Procedure & $\begin{array}{l}\text { Discharge } \\
\text { Diagnosis }\end{array}$ & Autopsy Diagnosis \\
\hline 1 & M & 69 & $\begin{array}{l}\text { Abdominal pain, } \\
\text { hepatic cirrhosis }\end{array}$ & $\begin{array}{c}\text { Abdominal } \\
\text { ultrasonography }\end{array}$ & Unknown & AAA rupture \\
\hline 2 & M & 78 & Liver transplant & Biopsy & Unknown & CAD, SCD \\
\hline 3 & M & 61 & Jaundice, fever & $\begin{array}{c}\text { Abdominal } \\
\text { ultrasonography }\end{array}$ & Sepsis & $\begin{array}{l}\text { Thrombosis of the } \\
\text { portal vein }\end{array}$ \\
\hline 4 & M & 67 & $\begin{array}{l}\text { Shock in hepatic } \\
\text { cirrhosis }\end{array}$ & $\begin{array}{c}\text { Abdominal } \\
\text { ultrasonography }\end{array}$ & Unknown & Bleeding peptic ulcer \\
\hline 5 & $\mathrm{~F}$ & 71 & Colon cancer & Right hemicolectomy & Sepsis & Sepsis, MODS \\
\hline 6 & M & 70 & Alcoholic liver disease & $\begin{array}{l}\text { Abdominal } \\
\text { ultrasonography }\end{array}$ & Unknown & Sepsis \\
\hline 7 & $\mathrm{~F}$ & 80 & $\begin{array}{l}\text { Decompensated liver } \\
\text { cirrhosis }\end{array}$ & EGD & Unknown & $\begin{array}{l}\text { Bleeding cirrhotic } \\
\text { nodule }\end{array}$ \\
\hline
\end{tabular}


Table 1. Cont.

\begin{tabular}{|c|c|c|c|c|c|c|}
\hline Case & Gender & Age & Admission Diagnosis & Procedure & $\begin{array}{l}\text { Discharge } \\
\text { Diagnosis }\end{array}$ & Autopsy Diagnosis \\
\hline 8 & M & 55 & Jaundice, hepatitis C & EGD & $\begin{array}{l}\text { Broncho- } \\
\text { pneumonia, } \\
\text { sepsis }\end{array}$ & Pulmonary embolism \\
\hline 9 & $\mathrm{~F}$ & 71 & Crohn's disease & Right hemicolectomy & $\begin{array}{l}\text { Intestinal } \\
\text { ischemia }\end{array}$ & Aspiration pneumonia \\
\hline 10 & M & 77 & Bleeding gastric ulcer & Surgical hemostasis & Unknown & Acute heart failure \\
\hline 11 & $\mathrm{~F}$ & 67 & Acute abdomen & $\begin{array}{c}\text { Abdominal } \\
\text { ultrasonography }\end{array}$ & Unknown & Bowel obstruction \\
\hline 12 & $\mathrm{~F}$ & 83 & Diarrhea & $\begin{array}{c}\text { Abdominal } \\
\text { ultrasonography }\end{array}$ & Unknown & Bowel obstruction \\
\hline 13 & $\mathrm{~F}$ & 87 & $\begin{array}{l}\text { Abdominal pain, } \\
\text { hepatitis } C\end{array}$ & EGD & Unknown & Pulmonary embolism \\
\hline 14 & M & 80 & Cholecystitis & $\begin{array}{c}\text { Laparoscopic } \\
\text { cholecystectomy }\end{array}$ & Unknown & CAD, SCD \\
\hline 15 & $\mathrm{~F}$ & 86 & $\begin{array}{l}\text { Stones of the main } \\
\text { biliary tract }\end{array}$ & ERCP & Sepsis & $\begin{array}{l}\text { Sepsis due to biliary } \\
\text { fistula }\end{array}$ \\
\hline 16 & M & 82 & $\begin{array}{l}\text { Cholecystitis, } \\
\text { cholangitis }\end{array}$ & ERCP & $\begin{array}{l}\text { Lithiasic } \\
\text { cholangitis, } \\
\text { sepsis }\end{array}$ & $\begin{array}{l}\text { Intestinal ischemia } \\
\text { with peritonitis }\end{array}$ \\
\hline 17 & M & 84 & $\begin{array}{l}\text { NSAIDs duodenal } \\
\text { ulcer }\end{array}$ & Surgical hemostasis & $\begin{array}{c}\text { Bleeding } \\
\text { duodenal ulcer }\end{array}$ & Acute heart failure \\
\hline 18 & $\mathrm{~F}$ & 69 & Duodenal perforation & $\begin{array}{l}\text { Laparotomy for } \\
\text { duodenal suture }\end{array}$ & Unknown & Bacterial pneumonia \\
\hline 19 & $\mathrm{~F}$ & 84 & Bowel obstruction & Abdominal X-ray & $\begin{array}{c}\text { Bowel } \\
\text { obstruction }\end{array}$ & $\begin{array}{c}\text { Bowel obstruction and } \\
\text { ischemia }\end{array}$ \\
\hline 20 & $\mathrm{~F}$ & 64 & $\begin{array}{c}\text { Bleeding from } \\
\text { branches of the RHA }\end{array}$ & TAE & $\begin{array}{c}\text { Bleeding } \\
\text { hepatic cancer }\end{array}$ & $\begin{array}{c}\text { Hemoperitoneum from } \\
\text { bleeding HCC }\end{array}$ \\
\hline 21 & M & 57 & Jaundice & ERCP & $\begin{array}{l}\text { Cardiocirculatory } \\
\text { collapse }\end{array}$ & Bacterial pneumonia \\
\hline 22 & M & 52 & Intestinal perforation & $\begin{array}{l}\text { Exploratory } \\
\text { laparotomy }\end{array}$ & $\begin{array}{l}\text { Stercoraceous } \\
\text { peritonitis }\end{array}$ & $\begin{array}{c}\text { Intestinal obstruction, } \\
\text { perforation }\end{array}$ \\
\hline 23 & $\mathrm{~F}$ & 57 & $\begin{array}{l}\text { Ascites in liver } \\
\text { cirrhosis }\end{array}$ & Paracentesis & $\begin{array}{l}\text { Liver cirrhosis } \\
\text { in ascitic phase }\end{array}$ & Ascites \\
\hline 24 & M & 81 & Hematemesis & EGD & $\begin{array}{c}\text { Cardiovascular } \\
\text { collapse during } \\
\text { EGD }\end{array}$ & $\begin{array}{l}\text { Bleeding duodenal } \\
\text { ulcer }\end{array}$ \\
\hline 25 & $\mathrm{~F}$ & 44 & Shock in gastroenteritis & $\begin{array}{c}\text { Abdominal } \\
\text { ultrasonography }\end{array}$ & $\begin{array}{l}\text { Cardiocirculatory } \\
\text { collapse }\end{array}$ & Myocarditis \\
\hline 26 & M & 69 & $\begin{array}{l}\text { Abdominal pain in } \\
\text { patient with AAA }\end{array}$ & Abdominal CT & $\begin{array}{c}\text { Cardiocirculatory } \\
\text { collapse during } \\
\text { CT }\end{array}$ & $\begin{array}{l}\text { Perforated duodenal } \\
\text { ulcer, peritonitis }\end{array}$ \\
\hline 27 & M & 93 & Shock & FAST scan & Unknown & $\begin{array}{c}\text { Bleeding esophageal } \\
\text { varices }\end{array}$ \\
\hline 28 & $\mathrm{~F}$ & 74 & $\begin{array}{l}\text { Persistent vomiting, } \\
\text { shock }\end{array}$ & Abdominal X-ray & $\begin{array}{l}\text { Cardiocirculatory } \\
\text { collapse }\end{array}$ & $\begin{array}{l}\text { Bleeding duodenal } \\
\text { ulcer }\end{array}$ \\
\hline
\end{tabular}

AAA, abdominal aortic aneurism; CAD, coronary artery disease; SCD, sudden cardiac death; MODS, multiorgan dysfunction syndrome; EGD, esophagogastroduodenoscopy; ERCP, endoscopic retrograde cholangiopancreatography; RHA, right hepatic artery; TAE, transcatheter arterial embolization; HCC, hepatocellular carcinoma; ARF, acute renal failure; and IBD, inflammatory bowel disease.

Out of the 28 cases, 15 (53.6\%) were men and $13(46.4 \%)$ women. The mean age was 71.9 years (range from 44 to 93 years).

Regarding the procedures performed, imaging methods were the most frequently involved (eleven; 39.2\%); in detail, abdominal ultrasonography was performed in seven cases (25\%), X-rays in two cases (7.1\%), and CT and FAST scan in the remaining two cases $(7.1 \%)$. Endoscopic procedures were executed in seven cases (25\%) and included esophagogastroduodenoscopy (EGD) (four; 14.2\%) and endoscopic retrograde cholangiopancreatography 
(ERCP) (three; 10.8\%). Surgical procedures were performed in a further seven cases $(25 \%)$, including laparoscopy (one; 3.6\%) and laparotomy (six; 21.4\%) (Figure 1). The remaining three cases $(10.8 \%)$ included in the study underwent post-transplant liver biopsy, transarterial embolization (TAE) of the bleeding branches of the right hepatic artery (RHA), and a paracentesis for the cytological evaluation of a peritoneal effusion.
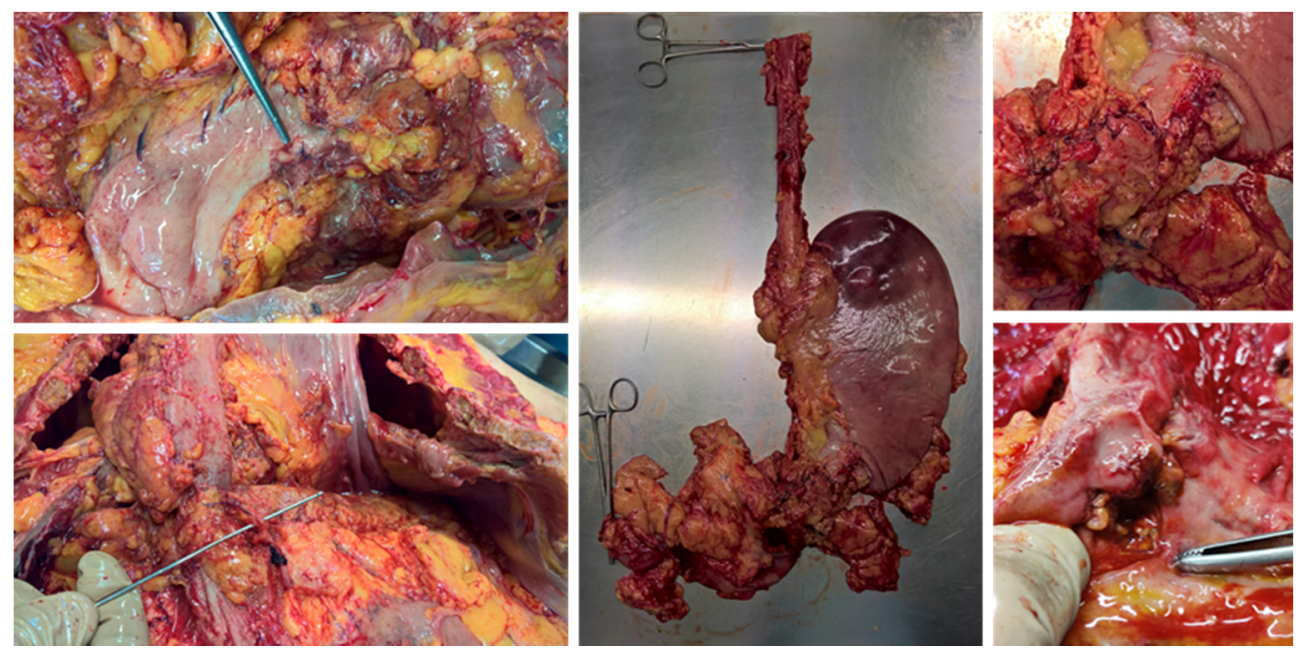

Figure 1. Autopsy investigation on case no. 17. Surgical treatment of bleeding duodenal ulcer and erosion of the superior pancreaticoduodenal artery. Evidence of correct surgical hemostasis.

From the analysis of the health documentation as well as from the audit with the physicians involved in the healthcare path, it emerged that the cause of death formulated in the clinical setting remained unknown in 12 cases (43\%). In the other 16 cases (57\%) the clinical diagnosis of death involved an acute cardiocirculatory disorder (five; $17.8 \%$ ), a disease of the gastrointestinal system and the liver (six; $21.4 \%$ ), and a systemic infectious process (five; $17.8 \%$ ).

In all cases, the post-mortem examination obtained objective evidence of the condition responsible for death. In detail, the pathologic diagnosis of death involved an acute cardiocirculatory disorder (six; $21.4 \%$ ), a respiratory disorder (five; $17.8 \%$ ), a disease of the gastrointestinal system and the liver (fourteen; 50\%), and a systemic infectious process (three; $10.8 \%$ ).

Comparing the evidence obtained through the examinations included in the present study and the clinical diagnoses, it was possible to highlight multiple discrepancies (Figures 2 and 3); in fact, post-mortem evaluations confirmed the clinical diagnosis in six cases $(21.4 \%)$. In 10 cases $(35.6 \%)$ the diagnosis was discordant, and post-mortem exams confirmed an alternative cause of death. In cases with unknown clinical diagnosis, autopsy and histopathological exams detected cardiovascular disorders (four; 14.3\%), acute respiratory failure (two; 7.1\%), hepatic and digestive disorders (five; 17.8\%), and a systemic infectious process (one; 3.6\%).

As regards the diseases underlying death it was possible to detect heterogeneous conditions, such as coronary artery disease (CAD) (two; 7.1\%), rupture of abdominal aortic aneurism (AAA) (one; 3.6\%), acute heart failure (AHF) (two; 7.1\%), myocarditis (one; 3.6\%), pulmonary embolism (two; 7.1\%), bacterial pneumonia (two; $7.1 \%$ ), aspiration pneumonia (one; 3.6\%), upper gastrointestinal bleeding (four; $14.3 \%$ ), hepatic bleeding (two; 7.1\%), intestinal perforation (two; 7.1\%), intestinal occlusion with or without ischemia (four; 14.3\%) (Figure 4), portal vein thrombosis (one; 3.6\%) (Figure 5), ascites (one; 3.6\%), and sepsis (three; $10.8 \%$ ). 


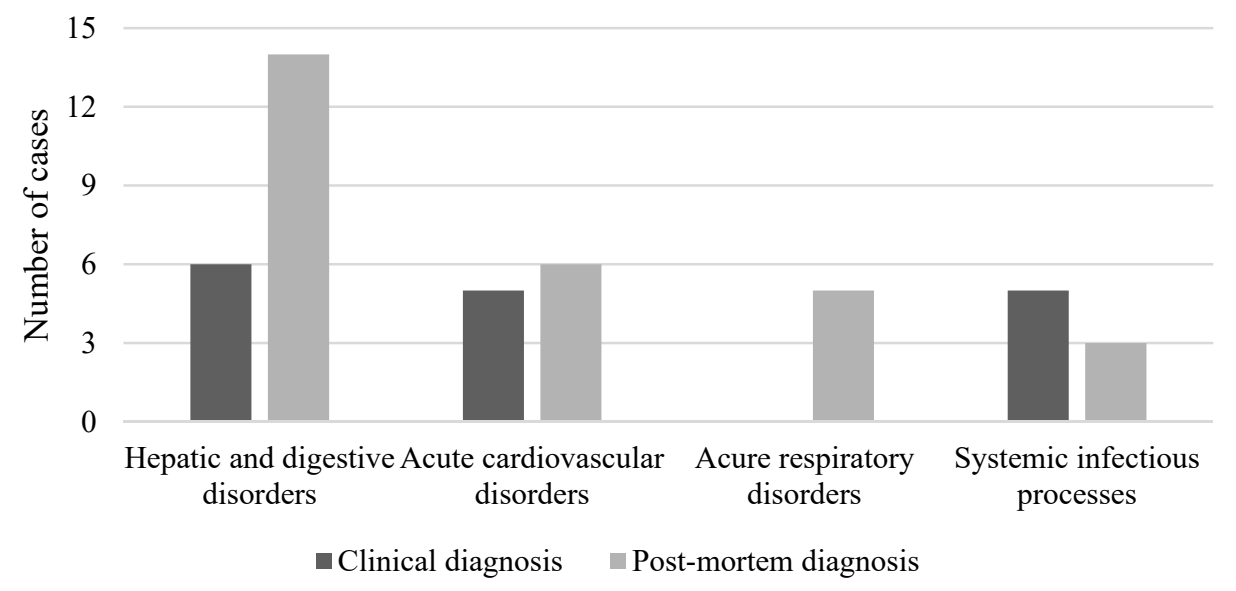

Figure 2. Distribution of cases according to the type of definitive diagnosis.
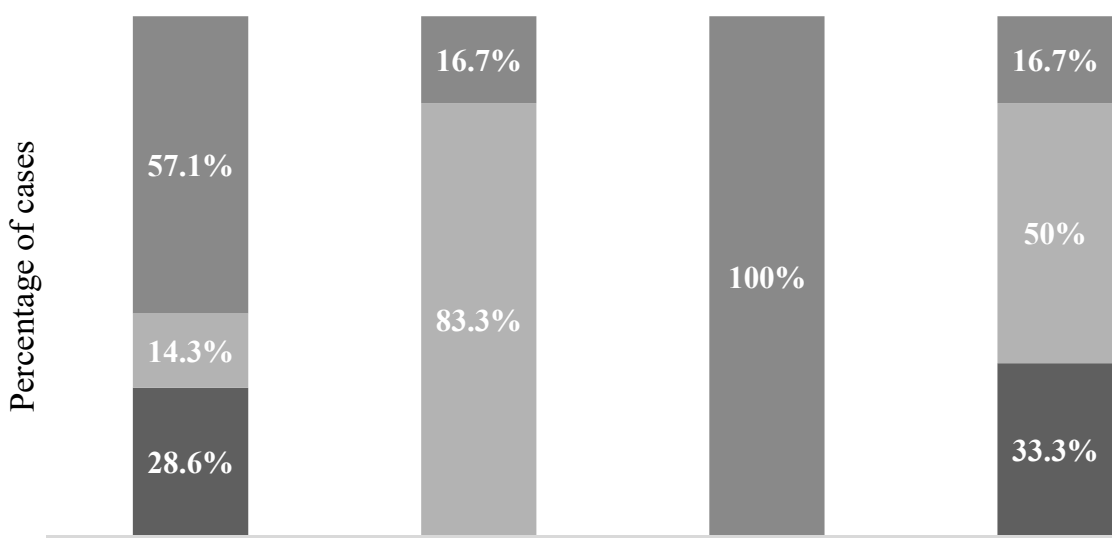

Hepatic and digestive Acute cardiovascular disorders disorders

Acure respiratory disorders
Systemic infectious processes

- Correct diagnosis $\square$ Uncorrect diagnosis $\quad$ Unspecified

Figure 3. Distribution of cases according to adequacy of clinical diagnosis.
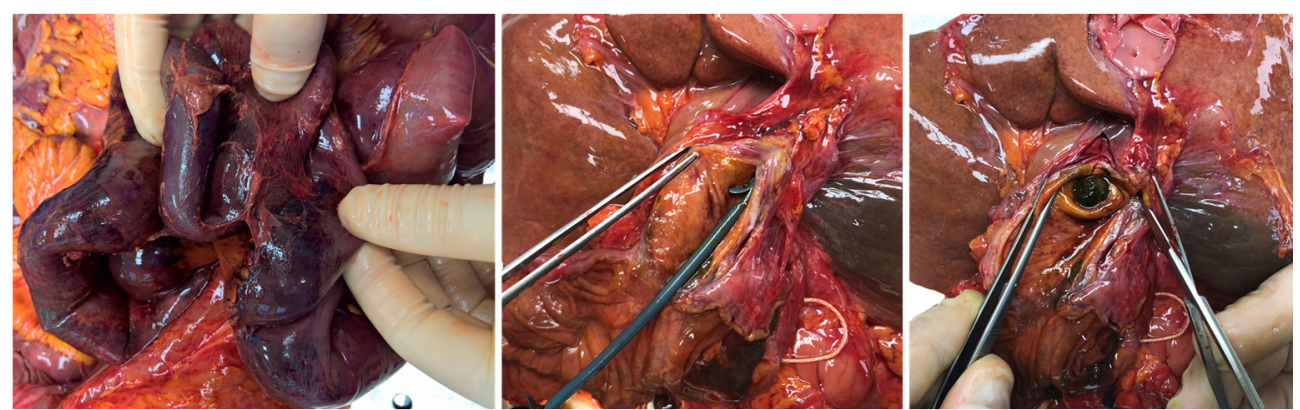

Figure 4. Autopsy investigation on case no. 16. Intestinal ischemia associated with peritonitis. The dissection of the biliary tract showed the correct positioning of an endoprosthesis and a lithiasis of the main biliary tract.

Concerning the relationship between clinical autopsy and litigation in the 28 cases analyzed, a significant ability of the former towards the latter was highlighted. In particular, in 22 cases $(78.6 \%)$, the participation in the autopsy of the physicians of the ward and the trusted physicians of the relatives of the deceased allowed the sharing of evidence useful for resolving doubts regarding the behavior of the health professionals involved in the care. In the remaining six cases $(21.4 \%)$, a dispute was initiated despite the carrying out of the autopsy; of these, two have been defined through an economic agreement due to the 
evident inadequacies of assistance, while four are still undefined due to the continuation of the judicial phase.
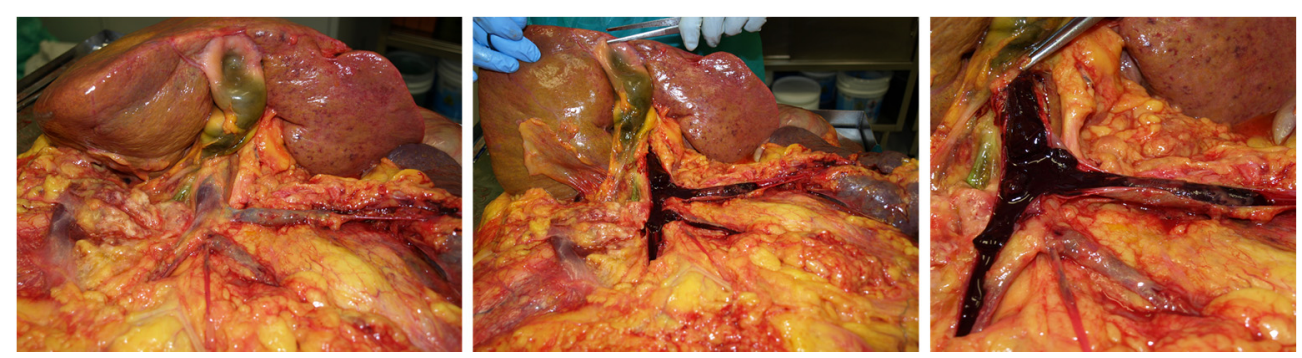

Figure 5. Autopsy investigation on case no. 3. Findings of massive thrombosis of the portal vein.

\section{Discussion}

Patient safety represents a growing challenge in proportion to the increasing complexity of care pathways. A deep understanding of diagnostic and therapeutic processes is a fundamental prerequisite for improving the quality of care. However, the assessment of the critical phases of providing care presents some asperities correlated to a scarce culture of error. In fact, a significant proportion of healthcare professionals are reluctant to report and learn methods based on adverse events because of shame or fear of compromising their reputation.

In US hospitals, a similar context translates into an increase in medical malpractice costs, which grew by an annual rate of $11.8 \%$ from 1975 to 2005 . Such an attitude towards the conduct put in place by health professionals determines the doubling of the disparity in the costs faced by physicians compared to those of the facilities; in fact, in 1975 the payments to be made by hospitals were 30\% lower than those of physicians, while in 2003 the first were $60 \%$ lower than the latter [29,30].

Outlining the economic weight of adverse events in terms of direct and indirect costs, it seems appropriate to underline how profitable risk management through reactive and proactive methods is able to limit the use of resources by healthcare facilities.

Among the different tools useful for risk mapping, the hospital autopsy undoubtedly represents an important diagnostic assessment for reactive analysis. Nevertheless, since the second half of the 20th century, in many countries the autopsy rate has undergone a massive decline; the factors involved are many, e.g., social, cultural, and religious beliefs [31], as well as the conviction of clinicians to be able to independently identify the pathological conditions and the related causes of death. Unfortunately, this drop in the rate of post-mortem examinations is a disadvantage, as there is a lack of valid support for medicine. In fact, the autopsy plays a role in protecting science, hospitals, and relatives of the deceased. Nonetheless, post-mortem assessment, representing the gold standard for defining the cause of death, provides valid support to health facilities and family members [32]. As demonstrated in the present study, a proactive risk-management approach can be implemented after a thorough analysis of the health records and audits with the health professionals.

The conducted study demonstrated the educational role of autopsy in orienting the practice of individual professionals and in providing useful insights for planning the policies of the health facilities. In particular, the autopsy definition of the critical-care issues and root causes facilitates the development of internal procedures for the reduction of unwanted events.

Concerning diagnostic imaging, the results obtained alternately show concordance and discrepancy with the literature data, highlighting interesting aspects relating to the diagnostic classification of patients, especially in emergency contexts. According to the current evidence, given the non-specificity of the symptoms, a timely approach based on the execution of abdominal ultrasound, CT scan, and X-rays in case of suspected bowel obstruction is of primary utility to establish any urgency; despite the dependence on the 
operator, ultrasound is the first assessment that should be performed to establish the real presence of an obstruction, especially in the case of involvement of the small intestine (sensitivity 90-92.4\%; specificity 96-96.7\%) [33,34]; a similar diagnostic capacity is comparable to the CT and better than X-rays (sensitivity 75\%; specificity 66\%) [35]. Conversely, CT scan is more accurate in identifying the cause of the obstruction. The evidence obtained from the present study made it possible to highlight how the exclusive execution of imaging methods did not always reach an exact diagnosis. In the enrolled cases, ultrasound was not decisive in diagnosing obstruction while conventional radiology demonstrated the presence of hydro-air levels when used. Such results essentially depended on operator-related factors and technical limitations in performing the exam. In suspected bowel perforations, ultrasound is indicated for the detection of pneumoperitoneum. The non-use of ultrasound in the present case series is justified by the fact that in one case, given the severity of the clinical conditions, an exploratory laparotomy was performed and in the other, given the positive history of AAA, a CT scan was performed to rule out a rupture; about the latter case, although the CT scan represents the method with the highest sensitivity in detecting intraperitoneal free gas [36-38], it was not possible to detect the radiological signs of perforation in relation to the patient's intra-procedural death. Furthermore, according to the ATLS protocol [39-41], the FAST scan was performed in a hemodynamically unstable patient, without however allowing the diagnosis of bleeding from esophageal varices.

Gastrointestinal bleeding is a common reason for emergency room access that frequently presents with hematochezia, melaena, or hematemesis; such presentation can lead to a condition of clinical instability which requires appropriate management [42,43]. In the suspicion of gastrointestinal hemorrhage, in the presence of stable clinical conditions, it is advisable to perform an endoscopic procedure for diagnostic and therapeutic purposes; this is the case of one of the study subjects who, despite the sudden cardiovascular collapse prevented the completion of the examination, was correctly initiated to the EGD in consideration of the positivity of the history for hematemesis and the stability of the clinical conditions. On the other hand, in cases of clinical instability, the criticality and non-specificity of the presenting symptoms have precluded the possibility of performing endoscopic procedures, allowing only to conduct imaging tests of limited diagnostic capacity in consideration of the intrinsic limitations of the methods.

In reference to the accuracy of the clinical diagnosis with respect to the autopsy diagnosis, the high percentage of incongruous or unknown diagnoses $(22 ; 78.6 \%)$ can be explained by the care context. In fact, most of the examined cases were characterized by hospitalizations in emergency operating units and critical conditions upon admission such as not to allow prompt classification. In other cases, the diagnostic process was limited by the inability to collect detailed anamnestic information. Again, in some cases (two; $7.1 \%$ ) the diagnostic process was interrupted by the patient's intraprocedural death. Focusing the discussion on cases of discrepancy between clinical and autoptic diagnosis, the highest diagnostic accuracy has been achieved in the field of gastrointestinal and hepatic diseases. On the other hand, excessive recourse to the diagnosis of cardiac death was found with a significant number of cases in which the cause was attributable to another system; moreover, in one case, autopsy made it possible to demonstrate the existence of a disease other than that hypothesized by the clinicians, despite the correct attribution to the cardiovascular system. A further relevant aspect was the finding of a low index of clinical suspicion for infectious and embolic diseases of the respiratory system. The data relating to the diagnostic pitfalls in the field of cardiovascular and respiratory diseases show absolute consistency with the evidence of the literature relating to the conspicuous amount of litigation deriving from similar events [44-46].

The experience gained in approaching the cases described has unquestionably demonstrated the value of transparency. The participation in the autopsy activities of all the parties involved allowed, in most cases, the effective reconstruction of the care process. Of particular interest is the experience of two procedures for surgical hemostasis of bleeding peptic ulcers in which inadequate surgical conduct was suspected following death; in these 
cases, the autopsy exploration of the surgical site demonstrated the tightness of the sutures, dispelling any hypothesis of inadequacy.

From the point of view of clinical risk, in addition to the audits carried out before each autopsy, reactive risk-management measures were implemented, such as the improvement of protocols for the diagnosis of intestinal obstructions. Currently, evidence-based proactive management measures are being evaluated.

Conclusively, the obtained results demonstrate the usefulness of the autopsy as a tool for preventing litigation through transparency and the prerogative of ascertaining the reality of the events. In particular, the objective vision provided by the port-mortem examinations makes it possible to dispel any suspicions regarding the inadequacies of healthcare. Likewise, post-mortem assessments have been shown to profitably contribute to risk management by identifying suboptimal steps in care pathways and allowing immediate analysis of the underlying causes of adverse events. Investment in hospital post-mortem diagnostics can therefore concretely enrich prevention systems and improve the safety of care. Therefore, it is appropriate to state that even in the field of risk management, "mors gaudet succurrere vitae" ("death delights in helping life").

Author Contributions: Conceptualization, S.D., M.Z., M.P. (Michela Peruch), M.C., M.P. (Martina Padovano), A.S., M.S. and V.F.; Data curation, S.D., M.Z., M.P. (Michela Peruch), M.C., M.P. (Martina Padovano), A.S., M.S. and V.F.; Investigation, S.D., M.Z., M.P. (Michela Peruch), M.C., M.P. (Martina Padovano), A.S., M.S. and V.F.; Methodology, S.D., M.Z., M.P. (Michela Peruch), M.C., M.P. (Martina Padovano), A.S., M.S. and V.F.; Supervision, S.D. and M.S.; Writing—original draft, S.D., M.Z., M.P. (Michela Peruch), M.C., M.P. (Martina Padovano), A.S., M.S. and V.F. All authors have read and agreed to the published version of the manuscript.

Funding: This research received no external funding.

Institutional Review Board Statement: The study was conducted according to the guidelines of the Declaration of Helsinki. The approval of the Ethics Committee was not necessary as all the procedures carried out are set by legislation (Presidential Decree 285/1990) as essential to ascertain the natural causes of death.

Informed Consent Statement: Informed consent was not necessary as for Italian legislation (Presidential Decree 285/1990) relatives cannot decide on the performance of the autopsy.

Data Availability Statement: The data used to support the findings of this study are available from the corresponding author upon request.

Conflicts of Interest: The authors declare no conflict of interest.

\section{References}

1. Costache, M.; Lazaroiu, A.M.; Contolenco, A.; Costache, D.; George, S.; Sajin, M.; Patrascu, O.M. Clinical or postmortem? The importance of the autopsy; a retrospective study. Maedica 2014, 9, 261-265.

2. Thorning, D. The Role of Autopsy in the Prevention of Medical Errors. Lab. Med. 2001, 32, 248-249. [CrossRef]

3. Pakis, I.; Polat, O.; Yayci, N.; Karapirli, M. Comparison of the Clinical Diagnosis and Subsequent Autopsy Findings in Medical Malpractice. Am. J. Forensic Med. Pathol. 2010, 31, 218-221. [CrossRef] [PubMed]

4. Madea, B.; Preuss, J. Medical malpractice as reflected by the forensic evaluation of 4450 autopsies. Forensic Sci. Int. 2009, 190, 58-66. [CrossRef]

5. Bove, K.E.; Iery, C.; Autopsy Committee, College of American Pathologists. The role of the autopsy in medical malpractice cases, I: A review of 99 appeals court decisions. Arch. Pathol. Lab. Med. 2002, 126, 1023-1031. [CrossRef] [PubMed]

6. Di Nunno, N.; Dell'Erba, A.; Viola, L.; Vimercati, L.; Cina, S.; Vimercati, F. Medical Malpractice A Study of Case Histories by the Forensic Medicine Section of Bari. Am. J. Forensic Med. Pathol. 2004, 25, 141-144. [CrossRef]

7. Scopetti, M.; Santurro, A.; Gatto, V.; Padovano, M.; Manetti, F.; D’Errico, S.; Fineschi, V. Information, Sharing, and SelfDetermination: Understanding the Current Challenges for the Improvement of Pediatric Care Pathways. Front. Pediatr. 2020, 8, 371. [CrossRef] [PubMed]

8. Juvin, P.; Teissière, F.; Brion, F.; Desmonts, J.M.; Durigon, M. Postoperative Death and Malpractice Suits: Is Autopsy Useful? Anesth. Analg. 2000, 91, 344-346. [CrossRef] [PubMed]

9. Mello, M.M.; Chandra, A.; Gawande, A.A.; Studdert, D.M. National costs of the medical liability system. Health Aff. 2010, 29, 1569-1577. [CrossRef] 
10. Gartland, R.M.; Bloom, J.P.; Fong, Z.V.; DeRoo, C.; Dwyer, K.; Quinn, G.; Lillemoe, K.; Mort, E. What Have We Learned From Malpractice Claims Involving the Surgical Management of Benign Biliary Disease?: A 128 Million Dollar Question. Ann. Surg. 2019, 269, 785-791. [CrossRef]

11. Tette, E.; Yawson, A.E.; Tettey, Y. Clinical utility and impact of autopsies on clinical practice among doctors in a large teaching hospital in Ghana. Glob. Health Action 2014, 7, 23132. [CrossRef]

12. Carlotti, A.P.; Bachette, L.G.; Carmona, F.; Manso, P.H.; Vicente, W.V.; Ramalho, F.S. Discrepancies between Clinical Diagnoses and Autopsy Findings in Critically Ill Children. A Prospective Study. Am. J. Clin. Pathol. 2016, 146, 701-708. [CrossRef] [PubMed]

13. Welsh, T.S.; Kaplan, J. The Role of Postmortem Examination in Medical Education. Mayo Clin. Proc. 1998, 73, 802-805. [CrossRef]

14. Madea, B. Medico-legal autopsies as a source of information to improve patient safety. Leg. Med. 2009, 11 (Suppl. 1), S76-S79. [CrossRef] [PubMed]

15. Pakis, I.; Yayci, N.; Karapirli, M.; Gunce, E.; Polat, O. Autopsy profiles of malpractice cases. J. Forensic Leg. Med. 2009, 16, 7-10. [CrossRef]

16. Choudhry, A.J.; Haddad, N.N.; Rivera, M.; Morris, D.S.; Zietlow, S.P.; Schiller, H.J.; Jenkins, D.H.; Chowdhury, N.M.; Zielinski, M.D. Medical malpractice in the management of small bowel obstruction: A 33-year review of case law. Surgery 2016, 160, 1017-1027. [CrossRef]

17. Seabury, S.A.; Chandra, A.; Lakdawalla, D.N.; Jena, A.B. On Average, Physicians Spend Nearly 11 Percent Of Their 40-Year Careers With An Open, Unresolved Malpractice Claim. Health Aff. 2013, 32, 111-119. [CrossRef]

18. Conklin, L.S.; Bernstein, C.; Bartholomew, L.; Oliva-Hemker, M. Medical malpractice in gastroenterology. Clin. Gastroenterol. Hepatol. 2008, 6, 677-681. [CrossRef] [PubMed]

19. Adams, M.A.; Allen, J.I. Medical Professional Liability in Gastroenterology: Understanding the Claims Landscape and Proposed Mechanisms for Reform. Clin. Gastroenterol. Hepatol. 2019, 17, 2392-2396. [CrossRef] [PubMed]

20. Schaffer, A.C.; Jena, A.B.; Seabury, S.A.; Singh, H.; Chalasani, V.; Kachalia, A. Rates and Characteristics of Paid Malpractice Claims among US Physicians by Specialty, 1992-2014. JAMA Intern. Med. 2017, 177, 710-718. [CrossRef]

21. Casali, M.B.; Mobilia, F.; Sordo, S.D.; Blandino, A.; Genovese, U. The medical malpractice in Milan-Italy. A retrospective survey on 14 years of judicial autopsies. Forensic Sci. Int. 2014, 242, 38-43. [CrossRef] [PubMed]

22. Valaske, M.J. Loss control/risk management. A survey of the contribution of autopsy examination. Arch. Pathol. Lab. Med. 1984, 108, 462-468. [PubMed]

23. Gartland, R.M.; Myers, L.C.; Iorgulescu, J.B.; Nguyen, A.T.; Yu-Moe, C.W.; Falcone, B.; Mitchell, R.; Kachalia, A.; Mort, E. Body of Evidence: Do Autopsy Findings Impact Medical Malpractice Claim Outcomes? J. Patient Saf. 2020. [CrossRef]

24. Start, R.D. Risk management, loss control and the autopsy. Br. J. Hosp. Med. 1993, 50, 576-578. [PubMed]

25. Osborn, M.; Burton, J.; Suvarna, S.K.; Royal College of Pathologists. Guidelines on Autopsy Practice: Postoperative Deaths. 2019. Available online: https:/ / www.rcpath.org/uploads/assets/4b6fdd98-eeaa-4f94-bb8ee9fc10217250/G174-Guidelines-onautopsy-practice-Postoperative-deaths.pdf (accessed on 28 May 2021).

26. Burton, J.L. Perioperative and postoperative deaths. In The Hospital Autopsy: A Manual of Fundamental Autopsy Practice, 3rd ed.; Burton, J.L., Rutty, G.N., Eds.; Hodder Arnold: London, UK, 2010.

27. Rutty, G.N.; Burton, J.L. The evisceration. In The Hospital Autopsy: A Manual of Fundamental Autopsy Practice, 3rd ed.; Burton, J.L., Rutty, G.N., Eds.; Hodder Arnold: London, UK, 2010.

28. Burton, J.L.; Saunders, S.; Hamilton, S. Medical procedures and devices encountered at autopsy. In Atlas of Adult Autopsy Pathology; Burton, J.L., Saunders, S., Hamilton, S., Eds.; CRC Press: Boca Raton, FL, USA, 2015.

29. U.S. Tort Costs: 2003 Update: Trends and Findings on the Costs of the U.S. Tort System. Available online: https: / www.omm.com/ omm_distribution/newsletters/client_alert_class_action/pdf/tort_costs_trends_2003_update.pdf (accessed on 15 June 2021).

30. Abbott, R.L.; Weber, P.; Kelley, B. Medical professional liability insurance and its relation to medical error and healthcare risk management for the practicing physician. Am. J. Ophthalmol. 2005, 140, 1106-1111. [CrossRef]

31. Burton, J.L.; Underwood, J. Clinical, educational, and epidemiological value of autopsy. Lancet 2007, 369, 1471-1480. [CrossRef]

32. Buja, L.M.; Barth, R.F.; Krueger, G.R.; Brodsky, S.V.; Hunter, R.L. The Importance of the Autopsy in Medicine: Perspectives of Pathology Colleagues. Acad. Pathol. 2019, 6. [CrossRef]

33. Gottlieb, M.; Peksa, G.D.; Pandurangadu, A.V.; Nakitende, D.; Takhar, S.; Seethala, R.R. Utilization of ultrasound for the evaluation of small bowel obstruction: A systematic review and meta-analysis. Am. J. Emerg. Med. 2018, 36, 234-242. [CrossRef]

34. Hollerweger, A.; Maconi, G.; Ripolles, T.; Nylund, K.; Higginson, A.; Serra, C.; Dietrich, C.F.; Dirks, K.; Gilja, O.H. Gastrointestinal Ultrasound (GIUS) in Intestinal Emergencies-An EFSUMB Position Paper. Ultraschall Med. 2020, 41, 646-657. [CrossRef]

35. Taylor, M.R.; Lalani, N. Adult small bowel obstruction. Acad. Emerg. Med. 2013, 20, 528-544. [CrossRef]

36. Kuzmich, S.; Harvey, C.J.; Fascia, D.T.; Kuzmich, T.; Neriman, D.; Basit, R.; Tan, K.L. Perforated pyloroduodenal peptic ulcer and sonography. Am. J. Roentgenol. 2012, 199, W587-W594. [CrossRef]

37. Lee, D.; Park, M.H.; Shin, B.S.; Jeon, G.S. Multidetector CT diagnosis of non-traumatic gastroduodenal perforation. J. Med. Imaging Radiat. Oncol. 2016, 60, 182-186. [CrossRef]

38. Stapakis, J.C.; Thickman, D. Diagnosis of pneumoperitoneum: Abdominal CT vs. upright chest film. J. Comput. Assist. Tomogr. 1992, 16, 713-716. [CrossRef] [PubMed]

39. Smith, Z.A.; Wood, D. Emergency focussed assessment with sonography in trauma (FAST) and haemodynamic stability. Emerg. Med. J. 2014, 31, 273-277. [CrossRef] 
40. Kortbeek, J.B.; Al Turki, S.A.; Ali, J.; Antoine, J.A.; Bouillon, B.; Brasel, K.; Brenneman, F.; Brink, P.R.; Brohi, K.; Burris, D.; et al. Advanced trauma life support, 8th edition, the evidence for change. J. Trauma Acute Care Surg. 2008, 64, 1638-1650. [CrossRef] [PubMed]

41. Farahmand, N.; Sirlin, C.B.; Brown, M.A.; Shragg, G.P.; Fortlage, D.; Hoyt, D.B.; Casola, G. Hypotensive patients with blunt abdominal trauma: Performance of screening US. Radiology 2005, 235, 436-443. [CrossRef]

42. Peery, A.F.; Dellon, E.S.; Lund, J.; Crockett, S.D.; McGowan, C.E.; Bulsiewicz, W.J.; Gangarosa, L.M.; Thiny, M.T.; Stizenberg, K.; Morgan, D.R.; et al. Burden of gastrointestinal disease in the United States: 2012 update. Gastroenterology 2012, 143, 1179-1187. [CrossRef]

43. Qayed, E.; Dagar, G.; Nanchal, R.S. Lower gastrointestinal hemorrhage. Crit. Care Clin. 2016, 32, 241-254. [CrossRef]

44. He, F.; Li, L.; Bynum, J.; Meng, X.; Yan, P.; Li, L.; Liu, L. Medical Malpractice in Wuhan, China. A 10-Year Autopsy-Based Single-Center Study. Medicine 2015, 94, e2026. [CrossRef]

45. Gatto, V.; Scopetti, M.; La Russa, R.; Santurro, A.; Cipolloni, L.; Viola, R.V.; Di Sanzo, M.; Frati, P.; Fineschi, V. Advanced Loss Eventuality Assessment and Technical Estimates: An Integrated Approach for Management of Healthcare-Associated Infections. Curr. Pharm. Biotechnol. 2019, 20, 625-634. [CrossRef] [PubMed]

46. Giraldi, G.; Montesano, M.; Napoli, C.; Frati, P.; La Russa, R.; Santurro, A.; Scopetti, M.; Orsi, G.B. Healthcare-Associated Infections Due to Multidrug-Resistant Organisms: A Surveillance Study on Extra Hospital Stay and Direct Costs. Curr. Pharm. Biotechnol. 2019, 20, 643-652. [CrossRef] [PubMed] 